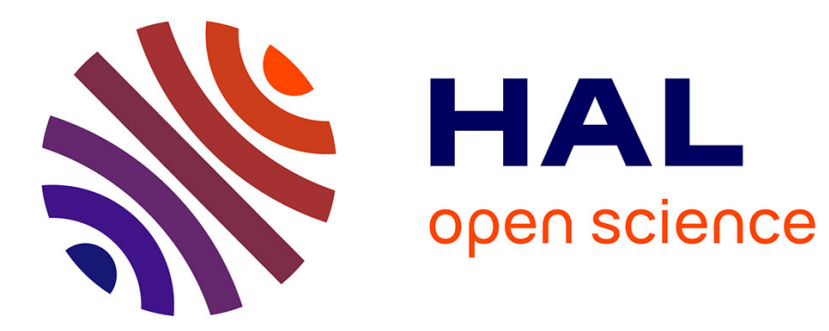

\title{
Trust and financial trades: lessons from an investment game wher reciprocators can hide behind probabilities
}

\author{
Radu Vranceanu, Angela Sutan, Delphine Dubart
}

\section{To cite this version:}

Radu Vranceanu, Angela Sutan, Delphine Dubart. Trust and financial trades : lessons from an investment game wher reciprocators can hide behind probabilities. 2011, 23 p. hal-00572384v3

\section{HAL Id: hal-00572384 \\ https://essec.hal.science/hal-00572384v3}

Submitted on 6 Mar 2012

HAL is a multi-disciplinary open access archive for the deposit and dissemination of scientific research documents, whether they are published or not. The documents may come from teaching and research institutions in France or abroad, or from public or private research centers.
L'archive ouverte pluridisciplinaire HAL, est destinée au dépôt et à la diffusion de documents scientifiques de niveau recherche, publiés ou non, émanant des établissements d'enseignement et de recherche français ou étrangers, des laboratoires publics ou privés. 


\section{CENTRE DE RECHERCHE}

TRUST AND FInANCIAL TRADES: LESSONS FROM an InVESTMEnt Game Where Reciprocators Can Hide Behind Probabilities

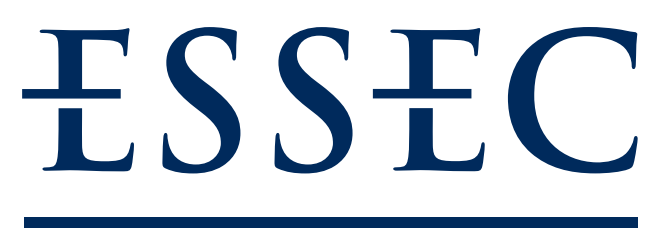

BUSINESS SCHOOL PARIS-SINGAPORE 


\title{
TRUST AND FINANCIAL TRADES: LESSONS FROM AN INVESTMENT GAME WHERE RECIPROCATORS CAN HIDE BEHIND PROBABILITIES
}

Radu Vranceanu, Angela Sutan†, Delphine Dubart ${ }^{\ddagger}$

\begin{abstract}
This paper shows that if a very small, exogenously given probability of terminating the exchange is introduced in an elementary investment game, more reciprocators will choose the defection strategy. Everything happens as if they "hide behind probabilities" in order to break the trust relationship. Investors do not alter their behavior in a significant way, at least not for a very small external risk. Financial assets all come with a predetermined and contractual probability that by the time when the buyer has to receive the reward for his investment, "bad luck" might have brought the asset value down to zero. In the light of the experimental findings, such trades would not provide a favorable environment for building trust.
\end{abstract}

JEL Classification Index: C90, D81, G00.

Keywords: Trust, Financial transactions, Experimental economics, Investment game, External randomness.

*ESSEC Business School and THEMA, PB 50105, 95021 Cergy, France. Mail: vranceanu@essec.fr

†ESC Dijon Bourgogne, BP 50608, 21006 Dijon, France. Mail: angela.sutan@escdijon.eu

‡ESSEC Business School, PB 50105, 95021 Cergy, France. Mail: dubart@essec.fr 


\section{Introduction}

From Aristote to present times, philosophers and political thinkers keep on claiming that there is something rotten in the realm of financial trades. Robert Solomon, a highly respected moral philosopher, pointed out that there is huge difference between the quest for profit of the traditional producer of goods, and the "abstract greed" of financial intermediaries (Solomon,1992). In the aftermath of the Great Recession of 2007-2009, many journalists, political leaders and even a few economists argued that the main culprit for this dramatic outcome was the "unleashed greed" of main players in the financial market. For instance, Laurence Summers, in his role of the US President economic advisor, argues that during the crisis "an abundance of greed and an absence of fear led some to make investments not based on the real value of assets, but on the faith that there would be another who would pay more for those assets" (Summers, 2009). Joseph Stiglitz (2010, p. 19) also notices that "Wall Streets' high rewards and single-minded focus on making money might attract more than its fair share of the ethically challenged, but the universality of the problem suggests that there are fundamental flows in the system". If such criticism is nowadays shared by a majority of people, there are not many convincing explanations of why trades in financial assets should be more prone to this kind of egoistic behavior than trades in any other goods.

In this paper we bring empirical evidence in favor of the assumption according to which, by contrast with many other markets, financial transactions do not provide a favorable environment for building trust. As pointed out by many scholars, trust is one important lubricant of a social system where resource allocation is based on voluntary exchange (e.g., Arrow, 1974; McKean, 1975; Noreen, 1988). Dasgupta (2000, p.50) emphasizes that: "Trust is of much importance precisely because its presence or absence can have a strong bearing on what we choose to do and in many cases what we can do. The clause concerning the inability to monitor others' actions in my definition of trust is crucial. If I can monitor what others have done before I choose my own action, the word 'trust' loses its potency". When, for one reason or another, the trust relationship is broken, transaction costs increase dramatically and markets might not perform in a smooth way 
their role of allocating resources.

There is no reason to believe that all markets (a) require and (b) generate the same amount of trust. On many markets the buyer knows what he is buying at the moment when he pays for the goods, thus trust is of little utility. In markets for "experience goods" (Nelson, 1970), the buyer will learn the quality of the product only after using it. Some transactions, such as the booming e-commerce, are sequential by nature: first the buyer pays the price, then he will get the product; there is always a risk that the quality of the good may fall below the product specifications. In these markets trust appears as a convenient way to economize on various transaction costs related to seller's would-be misbehavior (Gefen, 2000; McKnight et al., 2002).

Trust is much needed on financial markets. Indeed, the buyer of a financial asset owes a promise to get more resources in the future and, as is the case for all promises, there is an element of uncertainty about the ability of the seller to keep his word. In particular, both seller's misbehavior and exogenous (natural) events can bring the future value of the asset down to zero. It is important to notice that, compared to other markets, a predetermined probability that the asset might worth nothing is contractual in financial trades: by construction, the value of a financial asset at a future time depends on the state of the nature, a random event. The price the buyer pays for the asset is the mathematical expectation of the discounted utility connected to all possible outcomes, including the outcome that the asset will worth zero.

We argue that the trust relationship between participants to exchange is deeply undermined when such "external randomness" is part of the transaction. In particular, we posit that those playing the role of the asset seller (or trustee) will be more tempted to break the trust relationship if they can "hide behind probabilities", i.e., invoke "bad luck" when they have actually implemented their selfish defection strategy. They might do so because, ex-post, those acting in the buyer's role (or trustor) can no longer distinguish whether the adverse effects are due to the trustee's decision to break the trust relationship or to the external event. In general the trust relationship builds on a mutual assessment of what "good behavior" is. We expect trustees to care about the opinion of the trustors, even if they do not know each other. Since there is no enforcement mechanism at 
work, this tie is fragile. If a good pretext ${ }^{1}$ offers to them, some trustees would compromise with moral norms and behave in the most selfish way. ${ }^{2}$

In order to test for this theory, this paper develops an original variant of the traditional investment game (Berg, Dickhaut and McCabe, 1995). The latter has extensively been used to study the trust relationship. In the standard setup, an investor (player A) decides whether to transfer or not an amount of money to a reciprocator (player B). Before reaching the reciprocator, the transferred amount is augmented by the experiment administrator. Then the reciprocator decides whether or not to return some of the sum to the investor. Analyzing the problem as a one-shot, non-cooperative, sequential game, the dominant strategy for the reciprocator is to take all the money, thus the dominant strategy for the investor is not to transfer (this is the subgame perfect Nash equilibrium). However, in standard experiments, all the three possible outcomes are systematically observed: the one where the investor sends no money to the reciprocator, the partial trust outcome where the investor sends money and the reciprocator does not return a dime, and the mutual trust outcome where the investor sends money to the reciprocator and the later returns sometimes less, sometimes more than the amount initially invested. The mutual trust situation maps well the equilibrium of the cooperative game, wherein both players are better-off as compared to the non-cooperative equilibrium.

In the framework of the investment game, trust can therefore be interpreted as a (moral) value-driven way of building ties between participants to an exchange. Trust sets a natural limit on inefficient selfishness and brings about the Pareto-dominant cooperative outcome. People who reciprocate (at a cost for themselves) might do so because they want to reward a risky move of the person who placed his trust in them. Why investors send money in the first place is still a question open to debate. In general it is assumed that investors bet on the willingness of the trustees to reciprocate, and implement a strategy that maximize their expected return; their decision might also be driven by altruism, charity, or fairness considerations (see Camerer, 2003). In Western

\footnotetext{
1 Pretext : a purpose or motive alleged or an appearance assumed in order to cloak the real intention or state of affairs (Merriam-Webster Dictionary, 2010).

${ }^{2}$ Depending on the motive to invest, some trustors might also take advantage of this wiggle room and chose the no-trust strategy.
} 
societies, trust in others is, in general, considered as a virtue; an investor who chooses the trust strategy might thus infer some utility only from being perceived by the others as a trustful person.

We slightly modify the original set-up by introducing an element of randomness that disconnects the outcome observed by the investor from the action of the reciprocator. Like in the standard set-up, the investor decides whether or not to send a (fixed) amount to the reciprocator. ${ }^{3}$ If he transfers the money, a third party called Nature can decide whether to terminate the exchange and (the invested amount is then lost) or to continue it. Nature's move is random, the probability to terminate the relationship is common knowledge. If the exchange continues, the administrator multiplies the invested amount by a predetermined factor (bigger than one) and gives it to the reciprocator. The latter decide whether to keep all the money, or send back to the investor a predetermined sum (larger than the amount initially sent).

Thus, the only difference between this game and the traditional one consists in introducing an external risk of terminating the relationship between the investor and the reciprocator. Given that we want to make sure that changes in players' behaviors are induced by an alteration of the trust relationship and not by a reevaluation of the expected payoff of the investor, the external probability of termination must be very small. ${ }^{4}$ In the presence of this objective risk, when the investor sees no money forthcoming, he cannot say without ambiguity whether this is due to "bad luck" or to the reciprocator's "greed". Since the investor's assessment of the reciprocator's behavior is "blurred", the latter's feelings of shame or guilt might fade away.

Our experimental results corroborate this main assumption. The frequency of reciprocators who play the selfish strategy increases dramatically once that we introduce the objective risk. To the contrary, for a small risk, investors do not seem to anticipate the change in reciprocators' behavior; the frequency of investors who play the trust strategy does not decline in a significant way. This asymmetric response is removed for a larger objective risk.

Consequences at the macro level are straightforward: markets characterized by substantial external randomness - such as the financial market - would provide a more favorable environment

\footnotetext{
${ }^{3}$ A fixed amount variant allows to focus on the external risk as the single control.

4 The reciprocator plays after the Nature's move, so his payoff is certain.
} 
for the proliferation of extremely selfish behavior, as compared to markets where sellers cannot "hide behind the probabilities" in order to deceive buyers.

These results are much in line with the transaction costs literature that shows that increasing anonymity increases the probability of opportunity and deceitful behavior (Williamson, 1975; Milgrom and Roberts, 1992). While this literature emphasizes the role of reputation - agents extract information from observed behavior to update their beliefs about their trading partner, and cannot do so if transactions are anonymous - our paper focuses on the role of trust, that diffuse but fundamental moral tie between humans, that exists irrespective of monitoring and experience.

The paper is organized as following. The next section introduces the analytical context and the experimental design. Section 3 presents the main results. The conclusion and some policy implication are presented in the last section.

\section{Context and design of the experience}

\subsection{Related work}

There is a huge literature on trust in experimental games, such as surveyed for instance by Harvey (2002) and Tazdaï (2008). ${ }^{5} \quad$ Some of these papers have also analyzed the interaction between trust and external risk factors. For instance, Houser, Schunk and Winter (2010) study how the personal interaction in an investment game is modified when the reaction of the reciprocator is subject to induced randomness. Firstly they measure the risk aversion of the players. Then, they made subjects play four times a trust game, where the investor is a human, while the reciprocator is either a human without known history of moves, or a human with move history, or a random computer, or a computer replicating human history of moves. Results put forward that risk attitude is an important explanatory variable in games against the computer (objective risk), but not in the trust game (between humans). Camerer and Weigelt (1988) analyze the trust behavior in a finite horizon repeated game, with uncertainty about the "type" of the trustee, who can be more or less trustworthy. Investors upgrade their beliefs by observing the moves of trustees. When playing the game several times, players tend to discover the sequential equilibrium,

\footnotetext{
${ }^{5}$ See also Johnson and Mislin (2010) for a meta-ananlysis of 143 replications of the trust game.
} 
although some biases subside (people tend to cooperate more often than expected). Casari and Cason (2009) compare the outcome of a trust game played in the "strategy method" where the reciprocator must decide whether he will send back money to the investor before the latter makes his choice, with the classical setup where the reciprocator moves after he learns the investor's choice (the "game method"). They show that the amount send back is larger in the game method as compared to the strategy method.

A significant change in interpersonal interactions induced by external randomness has already been observed by Dana, Weber and Kuang (2007) in the framework of the dictator game. Under the "known" rule, the dictator can choose between the bundle ( 6 for him, 1 for the receiver) or the bundle ( 5 for him, 5 for the receiver). Subjects play the game several times and reach the standard outcome: many people are "generous", i.e., they prefer $(5,5)$ to $(6,1)$. Under the "unrevealed" rule, bundles can be either $(6,1)$ and $(5,5)$ or, a new combination, $(6,5)$ and $(5,1)$. At the outset of the game, the dictator sees only his own gain from choosing a bundle (6 or 5); he does not see the gain of the receiver. In order to find out the latter, he must push on a button. What the experiments have shown is that in general players do not press the button, and choose more often the bundle that provides them the largest payoff. Not only they "hide behind risk" in order to get the largest payoff, but they do not want to have this risk removed.

Several scholars have analyzed the contract game between a principal and an agent where the outcome depends on both the agent's effort and Nature's random draw. In presence of such objective uncertainty, if a project fails due to low effort, the agent can claim that he exerted the high effort, but he had bad luck. Keser and Willinger (2000; 2007) defined this situation as a "hidden action". They show that the standard theoretical hypothesis according to which the agent would accept the contract provided that his expected utility is slightly above zero does not hold in an experimental setting; indeed, in this context, agents require a "fair share" of the surplus in order to participate. Charness and Dufwenberg (2006) analyze a similar contracting game. One main result from their experiment is that pre-contractual communication limits the agent's recourse to "hidden actions". They argue that human sentiments such as shame and guilty could play an important role in containing opportunistic behavior. 
Other scholars have investigated the specificity of the trust relationship in financial markets. In a paper that combines experiments and observation of actual behavior, Karlan (2005) shows that persons identified as "trustworthy" in experimental games are less likely to default on loans in real life. Guiso, Sapienza and Zingales (2008) provide a theoretical and empirical analysis of trust as pertaining to the decision to buy shares. They notice that: "in determining whether to invest in a stock an individual has to assess not only what is the "true" distribution of returns, but also what is the possibility that the company is just a scam, that the manager steals all the proceeds, or that the broker absconds with the money instead of investing it" (Guido et al., 2008: p. 2563). Trust is then modelled as the subjective probability that investors assign to emergence of these "extreme bad events" that drive to zero the firm value, captured by the catchall situation "the firm cheats". Using Dutch and Italian micro data, they put forward that less trusting individuals are less likely to buy stock, and if they buy, they buy less. At difference with these papers that analyze the impact of trust on financial transactions (volume, diversification, investment strategies), our paper focuses on the reverse causality: how (financial) risk influences the quality of the trust relationship.

\subsection{Structure of the game}

The experience was cast as a one-shot sequential game between an investor (player A) and a reciprocator (player B). The two players do not know each other; the rule of the game and structure of payoffs is common knowledge. The experiment builds on the "game method", i.e. the reciprocator is called to make his choice after investor's move. The original contribution of the paper as compared to a standard investment game is the introduction of Nature, a virtual player (the computer) that can terminate the exchange between the investor and the reciprocator with a known probability $p$.

The sequence of decisions is the following:

- At the outset of the experience, player A gets 2 euros. He can decide to keep them or to transfer 1 euro to B. If he keeps them, the game is over.

- If he transfers the one euro, an external agent, called Nature, decides with a probability 
$p \geq 0$ whether to terminate the exchange between player $\mathrm{A}$ and player $\mathrm{B}$, or to continue it. Both players know this probability. If the interaction is terminated, the investor losses his investment and the reciprocator gets nothing. Nature's action is hidden: nor the investor, neither the reciprocator know what Nature did: they only see the payoff at the end of the game.

- If the interaction is continued, the administrator multiplies the one euro amount by five and gives them to $\mathrm{B}$.

- Player B has the choice between the defection strategy where he takes the whole amount, or the refund strategy, where he can keep 3 euros for himself and return two euros to player

A. The game ends.

Figure 1 presents the decision tree.

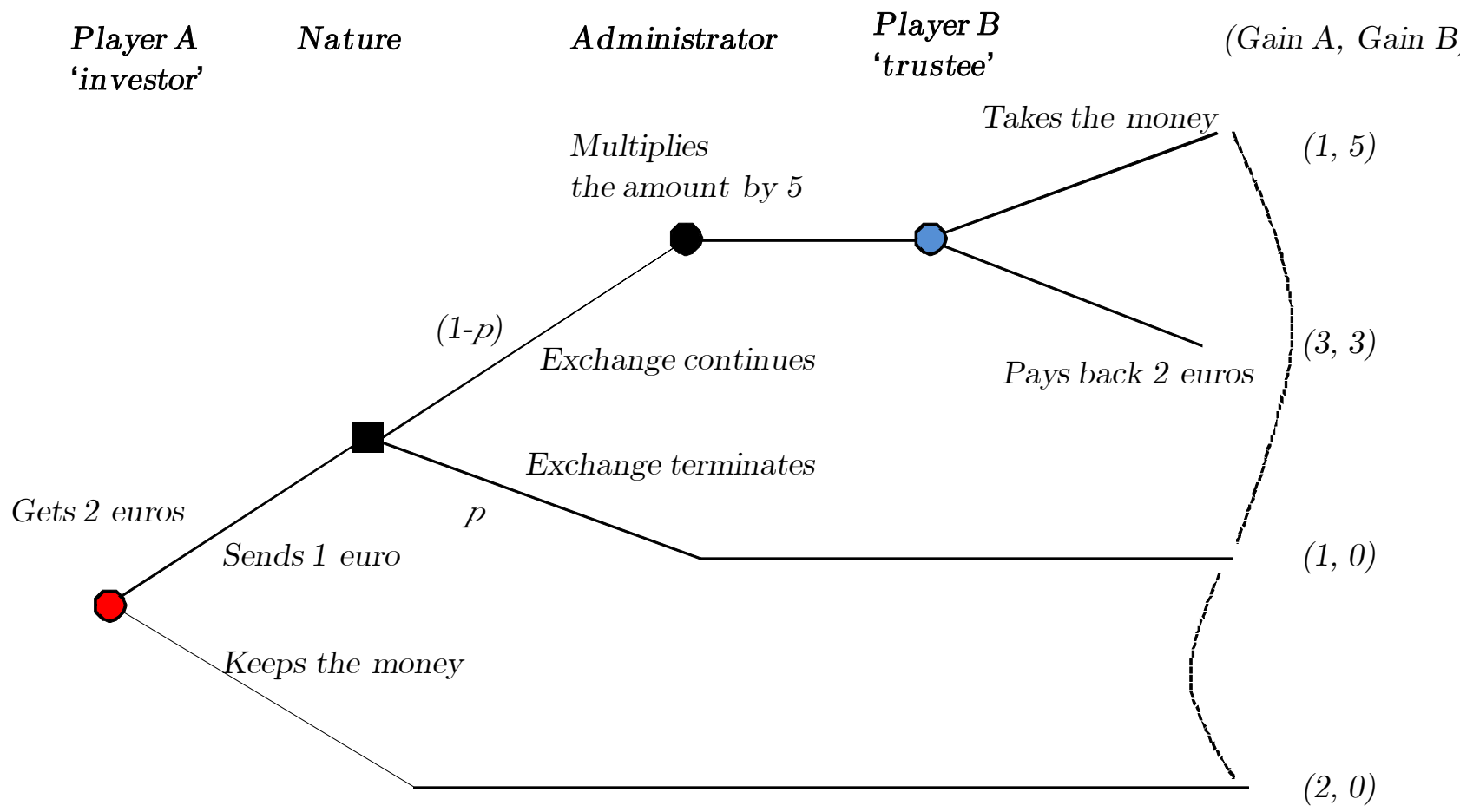

Figure 1: Decision Tree

The upper dotted curve indicates that an investor (Player A) who at the end of the game sees that his payoff is 1 euros, cannot infer from this information whether the reciprocator has played 
the defection strategy or Nature has terminated the relationship. This "blurred information" might attenuate reciprocators' feelings of shame or guilt for not rewarding a person who put their trust in them.

The lower dotted curve indicates that the reciprocator (Player B) who gets nothing will not be able to infer whether this implies that the investor did not play the trust strategy or whether Nature has terminated the exchange.

\subsection{Optimal and actual strategies; behavioral implications}

- The reciprocator (player B)

For $p=0$, the former game is identical to the elementary investment game (Berg et al. 1995). Under the elementary definition of rationality, the dominant strategy for the reciprocator is to take the money and leave. The traditional result in experimental economics according to which a majority of subjects choose the return strategy has been interpreted as trustworthiness.

Since the reciprocator plays after Nature, his attitude towards risk should not bear on his preferred strategy. Thus any observed change in the reciprocator's behavior when a positive probability of terminating the exchange is introduced can be directly related to the way how the investor interprets defection. When moving from $p=0$ to $p>0$, the investor who sees no money forthcoming can no longer identify the reason of this outcome: either the reciprocator has betrayed him, or bad luck occurred. The reciprocator might take advantage of this "wiggle room" in order to implement the defection strategy. ${ }^{6}$

We can thus introduce a more specific hypothesis to be tested:

H.1. The frequency of reciprocators playing the selfish strategy must be higher for $p>0$ than for $p=0$, even if $p$ is very small.

- The investor (player A)

Taking the same elementary definition of rationality, since the optimal strategy of the reciprocator is defection, the optimal rational strategy of the first player is not to invest. Yet in

\footnotetext{
6 This possibility has been documented by Dana et al. (2007) in the framework of a dictator game. Charness and Dufwenberg (2006) argued that the presence of an objective risk (no matter how small) provides the agent in a pricipal-agent contract game with a good pretext to pursue a hidden action, probably because his sentiments of shame or guilt are watered down to some extent.
} 
experimental settings a majority of investors send the money, which has been interpreted as trust in the other. Following Gambetta (2000) and Guiso et al. (2008), we can define trust as the positive subjective probability $\mu$ assigned by an investor to the event that player will return the investment and a reward (in our game, the reward of investing 1 euro is 2 euros). Furthermore, since people differ in their ability to trust the others, investors' own $\mu$ should follow a statistical distribution of p.d.f. $f()$ and c.d.f. $F()$; the support of these distributions is $[0,1]$. It is reasonable to assume that $f()$ is single-peaked. The shape of the distribution itself depends on the settings of the problem, and mainly on $p$.

Since the investor must decide whether to transfer the money before the realization of the objective risk, a large objective probability of Nature terminating the exchange $(p)$ might prompt him to play the no-trust strategy merely because for a given $\mu$, the expected gain declines. Thus, before moving to our empirical analysis, we must analyze the relationship between the objective probability and the trust decision.

For so doing, we assume that the investor will chose the strategy that brings him the largest (expected) monetary payoff. Adding a constant monetary payoff to acknowledge that the act of giving directly increases the satisfaction of the sender, for altruistic, charity or fairness motives, would not modify the basic reasoning. Changes in the frequency of investors that follow the notrust strategy depend in a significant way on whether changes in $p$ prompt investors to revise their beliefs about the reciprocator's behavior.

To keep this theoretical analysis simple, we follow Holt and Laury (2002) and assume that for small payoffs players are risk neutral. The expected gain of the investor who plays his "trust" strategy (i.e., invest the 1 euro) is:

$$
E\left[g_{A} \mid \text { trust }\right]=(1-p)[(1-\mu) \times 1+\mu \times 3]+p \times 1=1+2 \mu(1-p) .
$$

Player A prefers to transfer the euro to player B if the expected gain from the trust strategy is larger than the payoff from the no-trust strategy.

$$
E\left[g_{A} \mid \text { trust }\right]>\left[g_{A} \mid \text { selfish }\right] \Leftrightarrow 1+2 \mu(1-p)>2 \Leftrightarrow 2 \mu(1-p)>1 .
$$

Condition (2) allows to determine, for a given $p$, which is the critical probability $\hat{\mu}(p)$ below which 
no investor will engage in the trust strategy:

$$
\hat{\mu}(p)=\frac{1}{2(1-p)}
$$

with $\frac{d \hat{\mu}}{d p}=\frac{1}{2(1-p)^{2}}>0$. For $p=0$, we have $\hat{\mu}(0)=0.5$ In this context, investors that play the trust strategy in the elementary game $(p=0)$ are characterized by $\mu>0.5$. Notice that for $p=0.5$, we have $\mu=1$ : in this game, if the external risk $p$ is bigger than 0.5 , nobody will play the trust strategy.

For a given $p$, the frequency of investors that follow the no-trust strategy is $\operatorname{Pr}[\mu<\hat{\mu}(p) \mid p]=$ $F(\hat{\mu}(p) ; p)$. If investors can internalize the possible change in reciprocators' behavior if $p$ moves from 0 to a positive value, then more investors will become mistrustful. Formally, the distribution $F(\mu ; p>0)$ dominates the distribution $F(\mu ; p=0)$, that is $F(\mu ; p>0)>F(\mu ; p=0) \forall \mu \in[0,1]$. Let us denote the partial derivatives $F_{\mu}(\mu, p)=\frac{\partial F(\mu, p)}{\partial \mu}=f(\mu, p)>0$ and $F_{p}()=\frac{\partial F()}{\partial p} \geq 0$. Thus the total variation in the frequency $F$ is:

$$
d F(\mu, p)=\left[\frac{f(\mu, p)}{2(1-p)^{2}}+F_{p}(\mu, p)\right] d p
$$

As already mentioned, the main issue under scrutiny is a change in $p$ from zero to a small positive value. For an initial $p=0$, we can write:

$$
[d F(\mu, p)]_{p=0}=\left[0.5 f(0.5 ; 0)+F_{p}(0.5,0)\right] d p .
$$

If investors no not revise their beliefs about the reciprocator's behavior when $p$ changes, the partial derivative $F_{p}(0.5,0)=0$, then Eq. (5) becomes $[d F(\mu, p)]_{p=0}=[0.5 f(0.5 ; 0)] d p$. With $f(0.5 ; 0)<1$, it turns out that $[d F(\mu, p)]_{p=0}<0.5 d p$. If changes in $p$ do not prompt investors to revise their beliefs about the reciprocator's behavior, then small variations $d p>0$ in the neiborghood of $p=0$ should entail even smaller changes in the frequency of investors that follow the selfish strategy. For instance, if $p$ is raised from 0 to $1 \%$, it turns out that $[d F(\hat{\mu})]_{p=0}<0.005$; for $d p=0.1$, we have $[d F(\hat{\mu})]_{p=0}<0.05$.

We can introduce another testable assumption:

H.2. If moving from $p=0$ to a small positive $p$ does not induce a substantial change in 
investors' behavior, this implies that the latter do not anticipate subsequent changes in the reciprocator's behavior.

If changes in $p$ prompt investors to revise their beliefs about the reciprocator's behavior, small variations $d p>0$ in the neiborghood of $p=0$ can entail large changes in the frequency of investors that follow the selfish strategy. Indeed, if $F_{p}(0.5,0)=\alpha$, with $\alpha>0$, then $[d F(\mu, p)]_{p=0}>\alpha d p$.

The testable assumption is thus:

H.3. If moving from $p=0$ to small positive $p$ induces a substantial change in investors' behavior, this implies that the latter anticipates subsequent changes in the reciprocator's behavior.

In this elementary analysis we have assumed that the investor chooses the strategy that brings him the largest (expected) monetary payoff, given his beliefs about the reciprocator's response. Adding an exogenous gain to account for utility derived from altruism would not change this outcome. Yet those playing the investor's role could also derive some utility from being perceived as trustful by the others. Should this factor play a role too, one would expect more investors to play the no-trust strategy when moving from $p=0$ to $p>0$ because some investors could take advantage of the now blurred relationship (the reciprocator who sees no money forthcoming no longer knows whether the investor did not send the money or bad luck occurred).

\subsection{Experimental design}

The experiment included a total of 90 students from two French Business Schools (ESC Dijon and ESSEC) and were conducted in the Experimental Laboratories of the two institutions in April and May 2010. All the subjects were recruited from the student population of the schools, who answered to a call for paid decision experiments. The experimental design was presented via computer interface and all interactions were computerized. The programme was written in z-Tree (Fischbacher, 2007). Instructions were common knowledge. Experiments last for less than 30 minutes.

Half of the students played the role of the investor, called player A in the experiment, half or the students played the role of the reciprocator, called player B. Participants were randomly and anonymously paired as strangers. Each student was asked to play the game three times, for $p=0$, 
$p=0.01$ and $p=0.10$; the order of the three treatments was random, and pairs were recreated at each round. Nature's random move (continue/terminate relationship) was computerized, and the draw respected the displayed probability. Payoffs are exactly those indicated in the Decision Tree (Figure 1) and were paid in cash at the end of the experiment.

Table 1 indicates the location, time, number of subjects and nubmer of pairs for each session. In sessions 1 to 3 students had a fixed role (either Player A or Player B); in session 4 we allowed them to play both roles. ${ }^{7}$

\begin{tabular}{|l|l|l|l|}
\hline Place & Time & Number of subjects & Number of pairs \\
\hline Session 1: Dijon & March, 18, 2010 & 22 & 11 \\
\hline Session 2: Cergy & April, 13, 2010 & 22 & 11 \\
\hline Session 3: Cergy & April, 14, 2010 & 24 & 12 \\
\hline Session 4: Cergy & May, 5, 2010 & 22 & $22^{*}$ \\
\hline
\end{tabular}

Table 1. The organization of the experience

Rough data, main screen copies and the English translation of the instructions can be downloaded from the web address: https://sites.google.com/a/essec.edu/essec-experimental-la/results/trustand-financial-trades.

\section{Results and discussion}

Tables 2 and 3 summarize the main results. The first table presents investors' decisions, the second table presents reciprocators' choices, for each of the three treatements: no external risk $(p=0)$, small external risk $(p=0.01)$ and a larger external risk $(p=0.10)$.

\begin{tabular}{|l|l|l|l|}
\hline Treatment & Number of pairs & Number of transfers to B & Percentage of transfers \\
\hline$p=0$ & 56 & 34 & $61 \%$ \\
\hline$p=0.01$ & 56 & 31 & $55 \%$ \\
\hline$p=0.10$ & 56 & 25 & $45 \%$ \\
\hline
\end{tabular}

Table 2. Strategies played by investors (players A)

\footnotetext{
7 Two pre-test sessions were performed on March, 52010 in Dijon with 30 students. Three variants of the game were tested: this unframed fixed payment variant, an unframed, variable payment variant (amounts transferred were allowed to vary) and a framed variant, where player B was represented as a company needing an investment.
} 


\begin{tabular}{|l|l|l|l|l|}
\hline Treatment & Nature & $\begin{array}{l}\text { Number of } \\
\text { possible paybacks }\end{array}$ & $\begin{array}{c}\text { Number of } \\
\text { actual paybacks }\end{array}$ & Percentage of paybacks \\
\hline$p=0$ & 0 & 34 & 18 & $53 \%$ \\
\hline$p=0.01$ & 0 & 31 & 10 & $32 \%$ \\
\hline$p=0.10$ & 6 & 19 & 8 & $42 \%$ \\
\hline
\end{tabular}

Table 3. Strategies played by reciprocators (players B)

In addition, Figures 2 and 3 show the frequencies with which the two players have followed their trust strategies (transfer money for the investor, and pay back for the reciprocator). It should be emphasized that these frequencies apply to groups of different sizes.

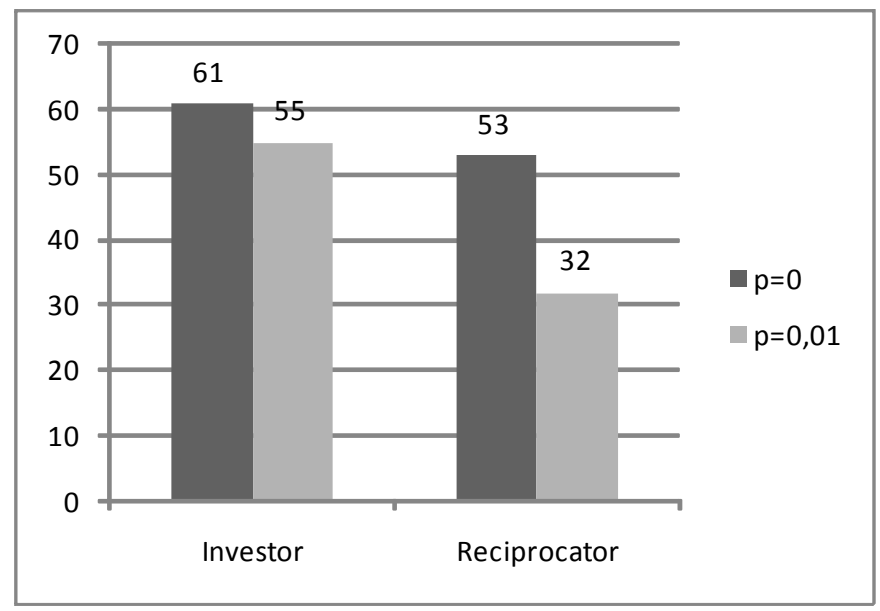

Figure 2: Investors playing the trust strategy; reciprocators playing the refund strategy, for $p=0$ and $p=0.01$, in percent of total possible moves.

- Results of the standard experiment: $p=0$

R0. These results are quite standard. Of the 56 pairs, players A sent money to players B for 34 times (i.e., $61 \%$ of the players adopted the trust strategy). Reciprocators paid back 18 times $(53 \%)$ and defected 16 times (47\%).

- Results of the test with a small probability of termination: $p=0.01$.

R1. When such a small objective default probability was introduced, 31 reciprocators got the 5 euros (an insignificant drop with respect to the former situation); only 10 of them chose to pay 


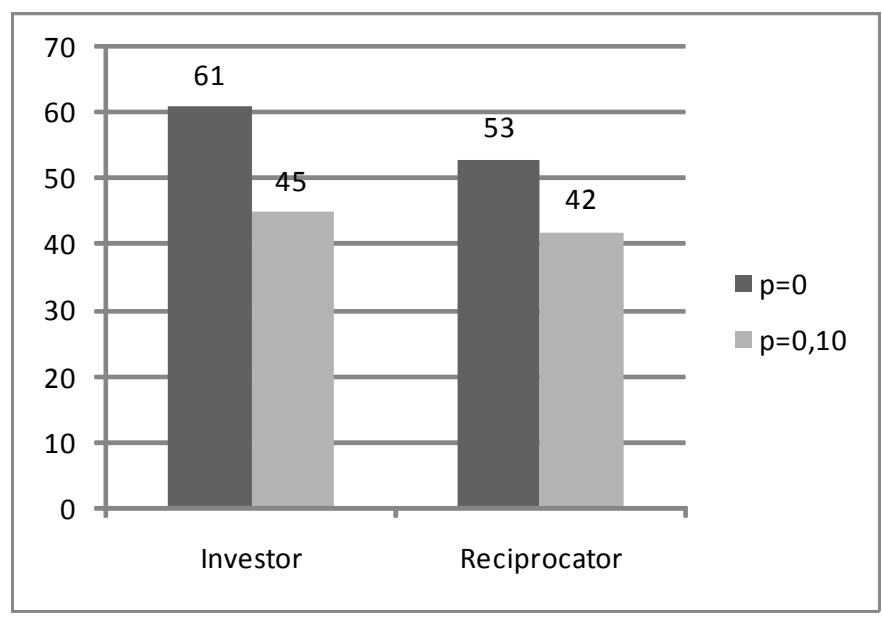

Figure 3: Investors playing the trust strategy; reciprocators playing the refund strategy, for $p=0$ and $p=0.10$, in percent of total possible moves.

back (instead of 18 refunds in the $p=0$ treatment); the frequency of reciprocators' defection raised thus from $47 \%$ to $68 \%$ (21/31). The change in the reciprocator's strategy is substantial (incremental rise in the defection rate: 21 percentage points). (While economically significant, the difference between the two situations is not statistically significant according to a test as demanding as the McNemar Chi-squared test: $\mathrm{p}$-value $=0.18$ ).

R2. However, despite the change in the reciprocator behavior, the investor did not alter in a substantial way their behavior, as if they were not been able to anticipate the change in reciprocators' behavior. Indeed, the number of transfers from player A to player B weekly declined, from 34 in the $p=0$ treatment to 31 transfers in the $p=0.01$ treatment. There is no statistical difference in investors' behavior: the McNemar Chi-squared test p-value $=0.66$.

\section{- Results of the test with a large probability of termination: $p=0.10$.}

It is important to notice that for $p=0.10$, not only did investors play less often the "no trust strategy" (only 25 investors out of 56 continue to transfer), but also in our experiment Nature terminated the relationship in 6 cases. Thus the number of actual transfers to the reciprocator is much smaller in the $p=0.10$ treatment than in both the $p=0$ and the $p=0.01$ treatments.

R3. In this treatment too, $58 \%$ of the reciprocators who get the funds played the defection strategy (i.e. 11/19), a higher frequency than in the $p=0$ treatment where the defection strategy 
was played by $47 \%$ of the reciprocators (incremental rise in the defection rate: 11 percentage points).

R4. A substantially lower number of investors played the trust strategy (send money), from $61 \%(34 / 56)$ in the $p=0$ treatment to $45 \%(25 / 56)$ in the $p=0.10 \%$ treatment, i.e. a reduction by 16 percentage points. The McNemar Chi-squared test for a substantial difference is significant at $6 \%$.

\section{- The Synthesis}

a) R1 and R3 corroborate H1: When an objective risk is introduced in a standard investment game, reciprocators hide behind probabilities and more of them implement the deception strategy. as already mentioned, this surge in opportunistic behavior in presence of external randomness has already been revealed by Dana et al. (2000) in a different experimental set-up (dictator game).

b) The rise in the reciprocators' defection rates is higher in the very small probability treatment $(p=0.01)$ than in the larger probability treatment $(p=0.10)$. While a straightforward explanation is not easy to fit, this idiosyncratic behavior might be explained if, in the higher risk situation, reciprocators do express some form of gratitude toward investors that have taken more risk to send them money (the reciprocation effect is stronger).

c) R2 corroborates H2. For a small external probability, despite a strong adjustment in reciprocators' behavior, investors do not alter in a significant way their strategies, as if they do not anticipate reciprocators' change in behavior. In Casari and Casson (2009) experiment with the trust game, investors also appeared limited in their ability to internalize changes in reciprocators' behavior.

d) According to R3, investors would correct their "error" for a larger probability of terminating the relationship. Risk aversion would induce a similar response; yet, for small gains it is highly probable that players are risk neutral. That investors who care about being perceived as trustful do also "hide behind probabilities" and chose the no-trust strategy, might provide another explanation. 


\section{Conclusion}

This paper provides new evidence on the effect of external randomness on the trust relationship between two parties to a trade. In particular, we have shown that if a very small and exogenously given probability of terminating the exchange ( $1 \%$ to be more specific) is introduced in a elementary investment game, the frequency of reciprocators who choose the defection strategy raises from $47 \%$ to $68 \%$. Reciprocators seem to hide behind the external risk in order to carry out their most selfish strategy. In the experiment, investors do not seem able to fully internalize this change in behavior, at least not for this very small external risk. The fact that subjects were young students, with a natural tendency to trust their colleagues, might have induced a bias. It would be interesting to run the experiment with more experienced players.

For sure, situations captured by such a simple experimental framework cannot claim to provide a comprehensive explanation for the extremely individualistic behavior observed in financial markets. In particular, financial transactions are both impersonal and not necessarily repeated. Then, as transaction costs theory points out, incentives for the players to build reputation are weak. Yet this argument does not explain why, during the last crisis, many banks that had sold an image of champions of long-term firm-customer relationships, have betrayed their clients and took on their books excessively high amounts of risk (Diamond and Rajan, 2009; Besancenot and Vranceanu, 2011). ${ }^{8}$

Our alternative explanation for this selfish attitude emphasizes the relationship between risk and trust. Indeed, an objective probability of default is a built-in feature of all financial transactions. Thus, when the value of an asset collapses, no one can tell whether this happened because the asset was poorly managed or because of mere bad luck. According to results of our experiment, the trust relationship is deeply undermined because the seller of the asset can "hide behind probabilities". He will resort more often to the selfish non-cooperative strategy as compared to sellers' behavior in markets where the objective risk of non-delivery is not contractual. With some

\footnotetext{
8 The Goldman Sachs scandal produced by the bank's participation in packaging and selling a pool of dubious mortgage loans on request by a hedge fund manager who bet against this pool of loans is illustrative for these ethical dilemmas. For years Goldman has claimed to be concerned with the long-term interest of its clients and partners (see "Greedy until proven guilty", The Economist, April 24th, 2010).
} 
caution, such systematic recourse to the defection strategy might be interpreted as "greed".

After the 2007-2009 crisis, many observers blamed the opacity of banks and complex financial assets for having provided a favorable playing ground for the most opportunistic and ruthless traders. Transaction cost literature has pointed out long time ago that increasing transaction anonymity increases the probability of selfish and deceitful behavior. Hence, increasing transparency of financial institutions has become probably the most consensual policy recommendation (Acharya et al. 2009; Stiglitz, 2010). Our paper does not run against this recommendation, yet it calls for cautious optimism: since even a small external risk of value destruction suffices to harm the trust relationship, increasing transparency might have only second order effects. Only by fully removing the external risk that one could create a trust friendly environment, but this task is difficult, since risk is an intrinsic component of all financial trades.

Acknowledgement 1 The authors would like to thank an anonymous referee, Tim Cason, Aurélie Dariel, Bernard Ruffieux and participants to the First International Conference of the French Association of Experimental Economics, Grenoble, 23-24 September 2010 for their remarks that helped them to improve this paper.

\section{References}

Acharya, Viral, Thomas Philippon, Matthew Richardson and Nouriel Roubini, 2009, The Financial Crisis of 2007-2009: Causes and Remedies, Financial Markets, Institutions $\mathcal{6}$ Instruments, 18, 2, pp 89-137.

Arrow, Kenneth, J., 1974, The Limits of Organization, Norton, New York.

Berg, Joyce, Dickhaut, John and Kevin McCabe, 1995, Trust, reciprocity and social history, Games and Economic Behavior, 10, pp. 122-142.

Besancenot, Damien and Radu Vranceanu, 2011, Banks' risk run: A signaling explanation, International Review of Economics and Finance, 20, 2, pp. 784-791.

Camerer, Colin, 2003, Behavioral Game Theory: Experiments in Strategic Interaction, Princeton University Press, Princeton, NJ.

Camerer, Colin and Keith Weigelt, 1988, Tests of a sequential equilibrium reputation model, Econometrica, 56, 1, pp. 1-36.

Casari, Marco and Thimothy N. Cason, 2009, The strategy method lowers measured trustworthy behavior, Economics Letters, 103, pp. 157-159

Charness, Gary and Martin Dufwenberg, 2006, Promises and partnership, Econometrica, 74, 6, pp. 1579-1601.

Dana, Jason, Roberto A. Weber, Jason Xi Kuang, 2007, Exploiting moral wiggle room: experiments demonstrating an illusory preference for fairness, Economic Theory, 33, 1, pp. $67-80$. 
Dasgupta, Partha, 2000, Trust as a commodity, In: Gambetta, D. (Ed.), Trust: Making and Breaking Cooperative Relations, Oxford University Press, pp. 49-72.

Diamond, Dougals W. and Raghumaram G. Rajan, 2009, The credit crisis: Conjectures about causes and remedies, American Economic Review: Papers and Proceedings, 99, 2, pp. 606-610.

Fischbacher, Urs, 2007, z-Tree: Zurich toolbox for ready-made economic experiments, $E x$ perimental Economics, 10, pp. 171-178.

Gambetta, Diego, 2000, Can we trust? In: Gambetta D.,(Ed.), Trust: Making and Breaking Cooperative Relations, Oxford University Press, pp. 213-237.

Gefen, David, 2000, E-commerce: the role of familiarity and trust, Omega, 28, pp. 725-737.

Guiso, Luigi, Paola Sapienza and Luigi Zingales, 2008, Trusting the stock market, Journal of Finance, 63, 6, pp. 2557-2600..

Holt, Charles A. and Susan K. Laury, 2002, Risk incentives and effects in lottery choices, American Economic Review, 92, pp. 1644-1655.

Houser, Daniel, Schunk, Daniel and Joachim Winter, 2010, Distinguishing trust from risk: an anatomy of the investment game, Journal of Economic Behavior and Organization, 74, (1-2), pp. 72-81.

Harvey, James S. Jr., 2002, The trust paradox: a survey of economic inquiries into the nature of trust and trustworthiness, Journal of Economic Behavior and Organization, 47, 3, pp. 291-307.

Johnson, Noel D. and Mislin, Alexandra, 2010, Trust games: A meta-analysis, GMU Working Paper in Economics, 10-38. Available at SSRN: http://ssrn.com/abstract=1702678

Karlan, Dean S., 2005, Using experimental economics to measure social capital and predict financial decisions, American Economic Review, 95, 5, pp. 1688-1690.

Keser, Claudia and Marc Willinger, 2007, Theories of behavior in principal-agent relationships with hidden action, European Economic Review, 51, 6, pp. 1514-1533

Keser, Claudia and Marc Willinger, 2000, Principals' principles when agents' actions are hidden, International Journal of Industrial Organization, 18, 1, pp. 163-185.

McKean, Roland N. 1975, Economics of trust, altruism and corporate responsibility, In: Phelps, E. S. (Ed.), Altruism, Morality and Economic Theory, Russel Sage Foundation, New York, pp. 29-44.

McKnight, Harrison D., Vivek Choudhury, Charles Kacmar, 2002, Developing and validating trust measures for e-commerce: An integrative typology, Information System Research, 13, 3, pp. 334-359.

Milgrom, Paul and John Roberts, 1992, Economics, Organization and Management, Prentice-Hall, Englewood Cliffs, UK.

Nelson, Philip, 1970, Information and consumer behavior, Journal of Political Economy, 78, 2, pp. 311-329.

Noreen, Eric, 1988, The economics of ethics: A new perspective on agency theory, Accounting, Organisations and Society, 13, 4, pp. 359-369.

Solomon, Robert E., 1992, Ethics and Excellence, Oxford University Press.

Stiglitz, Joseph E., 2010, Freefall. Free Markets and the Sinking of the Global Economy, W.W. Norton, New York. 
Summers, Lawrence H., 2009, Responding to an Historic Economic Crisis: The Obama Program, Remarks at the Brookings Institution, March 13, 2009, Online at: www.whitehouse.gov.

Tarik Tazdaït, 2008, L'Analyse Economique de la Confiance, De Boeck, Bruxelles.

Williamson, Oliver E., 1975, Markets and Hierarchies: Analysis and Antitrust Implications, The Free Press, New York. 
Pour tous renseignements :

- Centre de Recherche/Research Center Tél. 33 (0)134433091

research.center@essec.fr

- Visitez notre site

www.essec.fr

ESSEC BUSINESS SCHOOL PARIS

AVENUE BERNARD HIRSCH - BP 50105 CERGY

95021 CERGY-PONTOISE CEDEX - FRANCE

TÉL. +33 (0)134433000 - FAX +33 (0)1344330 01

www.essec.fr

ESSEC EXECUTIVE EDUCATION

CNIT - BP 230

92053 PARIS LA DÉFENSE - FRANCE

TÉL. +33 (0)146924900 - FAX +33 (0)146924990

http:// formation.essec.fr

ESSEC BUSINESS SCHOOL, SINGAPORE CAMPUS

100 VICTORIA STREET - NATIONAL LIBRARY BUILDING \#13-02

SINGAPORE 188064

TÉL. +65 $68849780-$ FAX +65 68849781

www.essec.edu

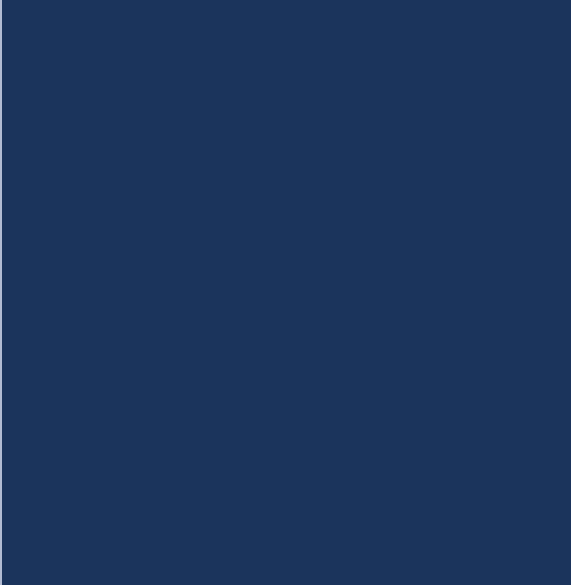

